\title{
Vana-Hiina Qini keisririigi valitsemissüsteemi olemusest ${ }^{1}$
}

\begin{abstract}
Tarmo Kulmar
Teesid: Legistlik riigivalitsemisteooria, mis oli suunatud valitseja täieliku kontrolli kehtestamisele ühiskonna üle ja keskvõimu tugevdamisele, on teadaolevalt esimene totalitaarse riigivõimu põhjendamise teooria maailma ajaloos. Sima Qiani kroonika analüüs näitab, et arvesse võttes kättesaadavaid andmeid Qini riigi loomise ja kokkuvarisemise, valitsemissüsteemi ülesehituse, majandusmeetmete, ühiskonnakorralduse, õigussüsteemi, religioonipoliitika ja ideoloogia, samuti armee ja välispoliitika kohta, oli antud juhtumil tegemist kindlasti varatotalitaarse riigiga, pealegi ilmselt maailma esimese totalitaarse suurriigiga.
\end{abstract}

Märksõnad: ideoloogia, legism, Qini keisririik, riigivõim, Vana-Hiina, varajane totalitarism, ühiskond

\section{Sissejuhatuseks}

Siinkirjutaja on juba varem teinud katse (vt Kulmar 2003 (2005): 25-39) postuleerida nn varatotalitaarse riigi mõiste ja tuua välja selle põhilised tunnusjooned. Eesmärgiks oli näidata ajalookroonikate andmetele toetudes, et Peruu inkade riigis kehtis eriline valitsemissüsteem, mille tunnused osutavad suuremal või vähemal määral varajasele totalitarismile.

Käesoleva artikli eesmärgiks on püüda näidata, et inkade riik ei olnud omasuguste seas esimene ega ainus, vaid võib-olla veelgi ilmsema varatotalitaarse riigi pretsedendi võib leida juba Vana-Hiina ajaloost - see on nimelt Qini impeerium. Siinkirjutaja ei väljenda seda mõtet esimesena. Otsesõnu on legismi totalitaarseks filosoofiaks nimetanud ka vene sinoloog Leonid Vassiljev (Vassiljev 1989: 108).

Ajaloolist ainest vahendab järeltulevatele põlvedele Vana-Hiina ajaloolane Sima Qian oma suurteose Shiji (Ajaloo ülestähendused) VI peatükiga "Qin Shihuang benji” (Olulisimad märkmed Qini esimese keisri tegudest). Sima 
Qian oli Hani dünastia keisri Wu Di historiograafi Sima Tangi poeg (snd u 135. aastal eKr). Oma kroonika kirjutamist alustas ta 104. aastal eKr ja lõpetas selle kolm aastat hiljem. Aastal $99 \mathrm{eKr}$ mõisteti ta keisri soosiku kohta tõe kirjutamise eest süüdi majesteedi solvamises ja karistuseks kastreeriti. Mõni aasta hiljem Sima Qian suri (Krjukov 1972: 12 jj). Kroonika VI peatükk on Qini riigi ajaloo allikana ainulaadne. Seda peetakse tõeseks ja usaldusväärseks just äärmiselt rohkele allikalisele baasile tuginemise tõttu; suur osa nendest algallikatest on kahjuks kaotsi läinud (Vjatkin 1972: 92-95).

Eriti tulemusrikkalt on Vana-Hiina filosoofiat ja riiklust uurinud vene sinoloogiakoolkond eesotsas Nikolai Konradi, Lev Menšikovi, Mihhail Krjukovi, Romuald Vjatkini, Vsevolod Taskini, Leonard Perelomovi ja Leonid Vassiljeviga. Seetõttu on loomulik, et siinkirjutaja kasutab legistliku filosoofia ja Qini riigipraktika hindamisel L. Perelomovi, M. Krjukovi ja L. Vassiljevi teedrajavaid uurimusi. Et mitte ühekülgseks jääda, on viidatud ka Stephen W. Durranti artiklile, mis sisaldab viiteid Ameerika sinoloogiakoolkonna tuntumatele esindajatele.

\section{Legistliku riigiõpetuse areng Vana-Hiinas ja esimesed rakendamiskatsed}

Legism (fajia) on vanimaid Hiina filosoofilisi õpetusi, mis kuulutab riigi prioriteetsust indiviidi ees, allutades inimelu ja tegevuse riigi huvidele.

Fajia õpetuse alusepanijaks oli 7. sajandil eKr elanud Qi riigi aukandja Guanzi ehk Guan Zhong ${ }^{2}$ (srn 645. aastal eKr), kes proovis seda rakendada ka tegelikkuses. Tema teos Guan-zi, mis sisaldas riigi- ja majandusõpetuse aluseid, pandi kirja 5. sajandil eKr. Qi vürstiriik, üks seitsmest nn võitlevate riikide ajastu Hiina riigist, toimis sellise majanduse ja kaubandusega. Seal valitses suur varanduslik diferentseerumine, kõrge maksukoormus ja seetõttu oli ka palju laostunud talupoegi, kes ebaseaduslikult maalt linnadesse põgenesid. Guan Zhongi keskseks ideeks oli: rikas riik - tugev sõjavägi. Rikka riigi aluseks pidas ta põllumajandust, tugeva riigi tunnuseks aga armeed. Guan Zhongi ühiskonnahierarhia jagunes tähtsuse järgi ametnikeks, maaharijateks, käsitöölisteks ja kaupmeesteks. Ta püüdis traditsioonilise kogukondliku korralduse asendada vertikaalse administratiivse süsteemiga ning jaotada rahvastiku efektiivse kontrolli ja maksukorralduse mõttes viieperelisteks üksusteks. Guan Zhong leidis, et valitseja peab olema tugev isiksus, kes söandab läbi viia riigi konsolideerimisele suunatud suuri majan- 
duspoliitilisi aktsioone. Esimesena Hiina ajaloos püstitas ta kontseptsiooni riigi valitsemisest seaduste alusel. Seadus on ülim, ka valitseja peab seda täitma. Karistus on moraalne mõjur. Rahvas peab võimu kartma nagu rasket haigust. Põllumajandus on rikkuse allikas. Kui rahvas on söönud, on ka hästi varustatud sõjavägi võitlusvalmis ja keegi ei söanda riiki rünnata. Kaubandus seevastu segab põllumajandust. Seda tuleb piirata või koguni keelata. Niisiis pooldas Guan Zhong autarkilist majandust.

Qi riigi valitseja käsul kirjutati Guan Zhongi seadused rituaalsetele pronksnõudele. Ometi tegi Guan Zhong vea, nõudes sotsiaalset ümberstruktureerimist. Seetõttu kaotas ta ülikkonna toetuse, sest tema ajal oli sugukondlik pärand veel liiga tugev (Perelomov 1981: 41-44; Vassiljev 1989: 9698).

Fajia ideede järgmisi ellurakendajaid oli 6. sajandil eKr Zi Chan, kes andis Zhengi vürsti nõunikuna 536. aastal välja rea seadusi. Pöörates suurt tähelepanu maaparandusele ja uudismaade ülesharimisele, tegi ta lõpu maa perioodilisele ümberjagamisele, jaotas elanikkonna viieperelistesse ühikutesse, keda sidus ringkäendusvastutus (esmakordselt Hiinas). Zi Chan kehtestas uue administratiivse haldusjaotuse eesotsas kuninga ametnikega, mille eesmärk oli viia kogukondlased pärusaristokraatia mõju alt valitseja otsesesse alluvusse ja seega kuninga (wang) isikuvõimu tugevdamine. Sama eesmärki teenis ka ametnikele vormiriietuse andmine, eristamaks neid pärusaristokraatiast, ning linna ja maa vaheliste erinevuste rõhutamine eesmärgiga rõhutada pealinna tähtsust. Leides, et aristokraatlikud suguvõsad on valitsejale ohtlikud, soovitas ta toetuda keskmistele ja madalamatele ühiskonnakihtidele. Samuti tunnistas Zi Chan kogukondlaste maaomandiõigust, mis ülikutele ei meeldinud.

Zi Chan oli riigiametnik, mitte teoreetik. Võib-olla just seetõttu oli ta oma reformides olude tundmise tõttu paindlikum kui Guan Zhong, viimata neid lõpuni (Perelomov 1981: 45-50; Vassiljev 1989: 99-100).

Tähtsaimaks legistliku filosoofia teoreetikuks, kellel samuti õnnestus oma ideid rakendada, oli Wei riigi vaesunud aristokraadiperekonnast pärinev Shang Yang (390-338 eKr), kellest sai Qini riigi valitseja Xiao Gongi nõunik ja kes suutis wangi veenda oma teoses Shang jun shu sisalduvat poliitilist programmi ellu viima (vt Shang Yang 1993: 139-240; Durrant 1987: 497498).

Majandus peab olema suunatud riigi tugevdamisele. Shang Yang pööras erilist tähelepanu maaharimisele ja põllumajandusele, et peatada maaharija vaesumine ja põgenemine maalt. Tuli kasutusele võtta uudismaid, sest maa ümberjagamine oli mõeldamatu; uusasunikud said soodustusi. Samas keelas ta põgenenud kogukondlastele peavarju anda. Samuti tuli legaliseerida maa 
ost-müük, mis oli suunatud pärusaristokraatia vastu. Nõnda saavutas ta võitluses aristokraatiaga jõukate kogukondlaste toe. Ta kehtestas riigiametite ja auastmete ametliku müügi, mis oli riigile tulus, luues sel viisil uue privilegeeritud ühiskonnakihi.

Nagu Guang Zhong, leidis ta, et kaupmeeste arvukust tuleb piirata. Kaubandus peab pigem olema riigi monopol ja riik peab kontrollima ka turuhindu. Valitseja ülesanne pidi tema arvates olema kehtestada riigi kontroll majanduse üle (Shang Yang 1993: 139-240; Perelomov 1981: 109-114; Vassiljev 1989: 108-121).

Riigijuhtimine ja ühiskond. Riik peab olema ühtne, terviklik, korrastatud ja monarhistlik (nii arvas ka Kong Fuzi). Shang Yangi erinevus aga seisnes järgmises: humaanne valitseja on ebareaalne, sest siis algab laos. Tuleb tugineda algele, milleks on seadus. Vajalik on absoluutne allumine valitseja sõnale. Seaduste toimimise tagab hästi funktsioneeriv riigiaparaat. Seaduse looja on valitseja. Valitseja on seaduseülene ega pea kellelegi aru andma. Seadus on ainuvõimu tugi. Samas peab seadus olema lähedases kooskõlas rahva tavadega. Rahvas peab võimu usaldama ja uskuma selle ilmeksimatusesse, selleks on vajalik selgitustöö. Aristokraatide võimu peab piirama ja nad allutama valitsejale. Shang Yang andis ka rahva definitsiooni: rahvas $(\mathrm{min}$ ) on vaeste ja rikaste ühtsus, sest ühed saavad teiseks ja vastupidi. Rahval ei ole mingeid poliitilisi õigusi. Tuleb tekitada ka usaldamatust ja hirmu üksteise suhtes (eriti ülemkihtides), et vältida altpoolt tulevat ohtu valitsejale. Riigi vägevus seisneb selle ainulisuses ja ühtsuses. Shang Yangi idee oli: nõrk rahvas - tugev riik. Vajalik on luua uut tüüpi riigiaparaat. Ainult nõrgast bürokraatiast võib saada valitseja teener, sest tugev bürokraatia kasvab üle pea.

Inimesekäsitus. Täiuslikul inimesel ei tohi olla nn parasiitomadusi. Need tulenevad konfutsionistlikest väärtustest, milleks on pilkelaulude laulmine, muusikategemine, heategevus, vanade tavade austamine, vanematest lugupidamine, vennaarm, omakasupüüdmatus, inimarmastus, ilukõne, teravmeelitsemine. See kõik viib inimese kõrvale riigi teenimisest.

Õiguskord. Üleastumised ja karistused tuleb diferentseerida - suur süü väärib ka karmi karistust. Shang Yang pidas kuuletumise ja hirmu sisendamise eesmärgil vajalikuks nn naabrivastutuse süsteemi (isa vastutab poja eest, naine mehe eest jne). Ühisvastutus armees lõpetas deserteerimise, sest tervet jagu tabas surmanuhtlus. Shang Yang rakendas ka sõdurite profülaktilise karistamist kepihoopidega jalataldade alla, et tekitada hirmu karistuse ees (Shang Yang 1993: 139-240; Perelomov 1981: 115-130; Vassiljev 1989: 108-121). 
Välispoliitilised vaated. Kong Fuzi õpetas, et eetilised voorused on omased ainult hiinlasele. Shang Yang lisas aga, et kahtlemata on hiinlane teistest rahvastest üle, kuid lähenemine peab olema pragmaatiline, lähtuma maa ja valitseja vajadusest ja kasust. Sõda nagu maahariminegi on tuluallikas ja üldse üks voorusi. Vallutussõjad on vältimatud (Shang Yang 1993: 139_ 240; Perelomov 1981: 131-155; Vassiljev 1989: 108-121.).

Shang Yangi ettepanekul viidi need ideed 356. aastal eKr suurel osal riigiseadustena ka ellu. 350. aastal eKr kehtestas ta uue administratiivjaotuse ja korrastas maksusüsteemi. Hiina ajaloolase Sima Qiani kroonika toob selle kohta rea näiteid. Külades loodi viie- ja kümneperelised rühmad, kus kehtis üksteise jälgimine ja ühisvastutus. Kes kuriteost ei teatanud, pidi pooleks raiutama; kes teatas, sai autasu; kurjategija varjajat tabas reeturi karistus. Kui peres oli rohkem kui kaks tööealist meest ja üks neist ei olnud abiellunud, pidi pere maksma kahekordse maksu. Kes hästi töötas ja palju tootis, vabanes ühiskondlikust töökohustusest, näiteks ehitustöödel. Sõjaliste teenete eest riigi ees sai ta valitsejalt auastme. Auastme saajal oli õigus varandusele. Väepealikut, kes võitles teisega oma huvides, karistati vastavalt tema motiivi ohtlikkusele. Muidugi avaldas pärusaristokraatia uuele valitsemissüsteemile suurt vastupanu, mis karmilt maha suruti (Sima Qian, VI ptk: 7-9; Perelomov 1981: 156-157; Durrant 1987: 498).

Niisiis leidis Shang Yang, et majandus, poliitika ja ühiskonnaelu peavad olema täielikult allutatud riigiaparaadile. Ta kehtestas Hiina bürokraatliku riigi alused, mis kehtisid pehmendatud kujul ka edasises Hiina ajaloos. Shang Yangi õpetus oli oma loomult selgelt antikonfutsianistlik ja totalitaarne. Samas demonstreeris Qini riigi tugevnemine Shang Yangi õpetuse elujõulisust ja konfutsianistidel oli sellega raske võidelda.

Lõpliku kuju andis legistlikule õpetusele Han Feizi (280-233 eKr). Hani riigi aristokraadi perekonnast pärit Han Feizi õppis tundma Shang Yangi õpetust ja tegevust Qini riigis. Kuna Shang Yangi loodud uus bürokraatia korrumpeerus ja Qinis algasid kuritarvitused, pööras ta erilist tähelepanu ametnikkonna loomise ja kujundamise küsimustele ning ametniku psühholoogiale. Ta väitis, et tark valitseja peab oskama varjata oma mõtteid ja tegutsemispõhjusi ametnike eest, olema riiklikult tark, paindlik ja vajadusel seadusi muutma. Han Feizi pühendus eelkõige riigivalitsemise taktikale (Vassiljev 1989: 211-215).

Eriti huvituti Han Feizi õpetusest Qini riigis, kus legism oli ametlik riigivalitsemissüsteem. Qini wang ja hilisem Hiina keiser (di) Shi Huangdi kutsus Han Feizi oma nõunikuks, kuid viimane vangistati Shi Huangdi hilisema kõikvõimsa ministri Li Si intriigide tõttu ja mürgitati vanglas (Sima Qian 1975: 53-58; Perelomov 1981: 166-169). 


\section{Qini keisririik kui Hiina esimene tsentraliseeritud riik (221-207 eKr)}

\subsection{Ajalooline taust: keisririigi tekkimine ja hävimine}

Qini riigi valitseja Ying Zheng võttis ette kogu Hiina ühendamise ja lõi esimese Hiina keisririigi. Ying Zheng sai 246. aastal eKr 13-aastaselt troonile. 234. aastal eKr kutsus ta oma esimeseks ministriks Li Si. Üksteise järel vallutati Qini alla ülejäänud Hiina riigid: 230. aastal eKr Han, 228 - Zhao, 225 - Wei, 223 - Chu, 222 - Yan ja 221 - Qi. 221. aasta aprilliks oli ta need kuus riiki ühendanud Qini alla. Alistunud armeed desarmeeriti, relvad koguti Qini pealinna Xianyangi, kus need valati kelladeks ja kujudeks. ${ }^{3}$ Ying Zhen võttis endale keiserlikuks tiitelnimeks Shi Huangdi 'Esimene Kõrgeim Käskija' (Sima Qian 1975: 62-63; Perelomov 1981: 191 jj; 1962: 34-38; Krjukov \& Perelomov \& Sofronov \& Tšeboksarov 1983: 15-16).

Keiser suri 210. aastal eKr 50-aastasena. ${ }^{4}$ Kirja viimaste korraldustega troonipärija Fu Sule ei saadetudki ära. Li Si, kes kartis rahutusi, varjas keisri surma. Surnukeha pandi tõlda ja rongkäik suundus, nagu oleks keiser elus, pealinna. ${ }^{5}$ Surmast teadsid vaid $\mathrm{Li} \mathrm{Si}$, keisri teine poeg $\mathrm{Hu} \mathrm{Hai}$ ja mõned lähemad ametnikud. Li Si mahitusel kuulutati keisriks 21-aastane Hu Hai, kes võttis nimeks Er Shi Huangdi 'Teine Kõrgeim Käskija', seaduslikule troonipärijale Fu Su'le saadeti aga “ausurma” ettepanek. Er Shi laskis hukata kõrgemad ametnikud ja mõrvata oma vennad. Ka riigi "arhitekt" Li Si ise leidis varsti "ausurma”. Sagenevad mässud sundisid keisrit varjama end palee salaruumis ja pidama nõu ainult uue nõuniku Zhao Gai'ga. Viimane korraldas juulis 207. aastal eKr riigipöörde ning Er Shi lõpetas elu sunnitud enesetapuga. Sama aasta lõpus tapeti ka viimane Qini keiser Zi Ying. See sündmus tähendas 14 aastat püsinud Qini impeeriumi lõppu. Puhkenud kodusõda lõppes alles 202. aastal eKr Hani keisririigi loomisega dünastia rajaja Liu Bangi poolt (Sima Qian 1975: 86-98; Perelomov 1962: 182-208; Perelomov 1981: 191-204; Krjukov \& Perelomov \& Sofronov \& Tšeboksarov 1983: 370).

Qini keisririik tekkis seega sõjaliste vallutuste tulemusena, kestis, nii nagu enamik totalitaarseid riike, suhteliselt lühikest aega ja lagunes kuhjunud sisevastuolude tulemusena. 


\subsection{Administratsioon. Riigiaparaadi ülesehitamine}

Li Si nõuannete järgi loodi keskusele allutatud riigiorganid: sõja-, kohtu-, rahandus-, oukonna-, kommete-, ihukaitseministeerium ja prokuratuur. Kojaministril (shaofu) Li Si'l oli hiigelsuur võim. Talle allusid niisutussüsteemid, soola- ja rauakaubandus, keisrikojale tehtav käsitöö ja relvalaod. Ta oli riigi pitsatihoidja ja kõrgeim usuametnik, talle allus keisri ihukaitse. Seaduste ja kohtuotsuste täitmise järele valvas riigikontroll. Riik jagunes 36 provintsiks, mis omakorda jagunesid piirkondadeks, viimased veel ringkondadeks. Igas provintsis ja piirkonnas olid oma kuberner, kantselei ja kõikide ministeeriumide esindajad.

Li Si lõi riigi jaoks ühtse raha- ja mõõtühikute süsteemi. Juba 221. aastal eKr hakati vermima kindla kaalu ja kujuga vask-, hõbe- ja kuldmünte. Samal aastal viidi läbi kirjaviisi ühtlustamine, millel oli suurriigi ülesehitamisel otsustav tähtsus (Sima Qian: 64-65; Perelomov 1962: 44-46; Perelomov 1981: 191-204; Krjukov \& Perelomov \& Sofronov \& Tšeboksarov 1983: 16-18).

Qini riigis oli niisiis olemas efektiivselt toimiv riigiaparaat, mille abil teostas rahvast isoleerunud võimueliit tänu bürokratiseerunud ametnikkonnale rangelt tsentraliseeritud keskvõimu, püüdes hoida riigielu nähtusi võimalikult täieliku kontrolli all.

\subsection{Majandus ja infrastruktuur}

Majanduses asetati rõhk põllumajanduse edendamisele. Majandusüksuseks ei olnud enam külakogukond, vaid peremajapidamine. Kogukondlaste-maaharijate olukord isegi paranes veidi võrreldes varasemaga, sest talupoegade maksustamine normeeriti ja allutati riigile. Pärusaristokraatia ei saanud enam takistamatult nõuda ülemääraseid koormisi. 221. aastal eKr seati sisse hingemaks ja 216. aastal talunditele maamaks. Kaubandus muutus teisejärguliseks: toetati küll suurkaupmehi ja suurte töökodade omanikke, ent väikekaupmehed langesid ühiskondlikus hierarhias isegi vabast talupojast madalamale - talupojale näidati, et maalt pagemisel ei oota teda midagi head. Nt hakati ühiskondlikele töödele sunniviisil mobiliseerima esmalt väikekaupmehi, siis kahtlast päritolu isikud ja lõpuks maaharijaid. Jõukamad kaupmehed said aga end vabaks osta ja neil lubati koguni auastmeid osta.

Riik nõudis regulaarset ühiskondlikku tööteenistust paljudes valdkondades: Suure Müüri, kindluste, teede, piirikaitserajatiste ja keiserlike palee- 
de ehitusel, maismaa- ja veetranspordis, niisutussüsteemide rajamisel, uudismaade ülesharimisel. Kohustusi ei pidanud kandma ametnikud, samuti need, kes suutsid end vabaks osta. Maa ühendamine heas korras teedevorrguga aitas kaasa ääremaade asustamisele ja uudismaade ülesharimisele, mis edendas riigi majandust. Keiser ise reisis palju ja kontrollis seaduste täitmist kohtadel (Sima Qian 1975: 66-71; Perelomov 1962: 111-117; Perelomov 1981: 191-204; Krjukov \& Perelomov \& Sofronov \& Tšeboksarov 1983: 28-29).

Qini riigis oli niisiis olemas suundumus riigi (s.o keisri) omandi domineerimisele vana aristokraatia eraomandi suhtes, autarkilisele majandusele ning tootmise ja tarbimise planeerimisele, kehtisid üleüldine töökohustus ja kunstlikult loodud turusuhted ning riikliku sunduse rakendamine suurprojektide elluviimisel.

\subsection{Sotsiaalelu ja meetmed ühiskonnakorralduses}

Juba 221. aastal eKr kogus keiser 120000 aristokraatide ja suurkaupmeeste perekonda pantvangidena pealinna Xianyangi, et allutatud riigid ei söandaks hakata taastama sõjavägesid. Represseerides vana aristokraatiat, suhtus ta soosivalt uude ametnikkonda ja Qinist pärit ohvitseridesse. Armee juhtivkoosseis nimetati nüüd viimaste seast. Kõikides provintsides loodi Qini garnisonid. 220. aastal eKr tõstis Shi Huangdi kõigi Qinist pärit ohvitseride auastet.

Indiviidil oli vabadus valida tegevusala vaid horisontaalselt oma ühiskonnakihis, ühiskonnahierarhia vertikaalteljel üles-alla liikumine seevastu oli ainult kõrgeima võimu lubada ja otsustada. Riigi eesmärk oli muuta ametnikud soodustuste ja karistuste abil keisrile kuulekaks, selleks toimis ka auastmete ostu ja müügi süsteem. Uudismaadele ja piirialadele asustati riigi teistest osadest sunniviisil ümber terveid kogukondi. Ümberasustatud elasid sõjaväestatud asulates kindla režiimi kohaselt, kuid nad olid vabastatud muudest ühiskondlikest kohustustest, välja arvatud sõjaväeteenistus. Kogukondlastel ja väikekaupmeestel oli riigis loata elukohavahetus ja vaba reisimine keelatud.

Kuna aktiivse sise- ja välispoliitika kulutused kaeti põhiliselt maaharijate töö arvelt ning et töö- ja sõjaväekoormised kasvasid, tekkis soodesse ja mägedesse pagenutest arvukas asotsiaalne ühiskonnakiht, kellest sai riigi lõpuaastate kodusõjas üks Hani dünastia võidule viijaid (Sima Qian 1975: 66-77; Perelomov 1962: 111-117; Perelomov 1981: 191-204; Krjukov \& Perelomov \& Sofronov \& Tšeboksarov 1983: 36 jj). 
Qini riigis reglementeeriti niisiis riigi kontrollmehhanismide abil ühiskonna struktuuri, piirati liikumis- ja elukutsevaliku vabadust, eelistati ühtesid ühiskonnakihte teistele, deporteeriti osa elanikkonnagruppe riigi muudesse kohtadesse ja assimileeriti teiste sekka.

\section{5. Õiguskord}

Alates 221. aastast eKr viidi läbi kommete ja seaduste ühtlustamine ning loodi kirjutatud seadustik, mille alusel toimetati õigusemõistmist. Kõikides provintsides tegutsesid pealinnast määratud kohtunikud, otsuste täideviijad ja järelevalveametnikud. Kogukondlastele kehtestati viie- või kümnepereliste üksuste kaupa ringkäendusvastutus, mis tähendas nii üksteise jälgimist kui ka seda, et ühe pere liikme süüteo korral karistati kogu ringkäendusüksust. Keiser Er Shi Huangdi laiendas süsteemi ka aristokraatiale ja kõrgametnikele, et oma vendi seadusrikkumiselt tabades kõigist korraga lahti saada. Sel moel kannatasid väga paljud süütud inimesed, kelle vara konfiskeeriti ja kes mõisteti riigiorjusse või hukati. Seaduste tõlgendamisel püüti keelata seda, mis ei olnud lubatud.

Surmanuhtlust kohandati enamasti küll riigivastaste tegude eest, kuid selliseid tegusid oli palju. Ainult kõrgülikuid ja -ametnikke võis oodata nn ausurm, milleks keiser saatis mõõga. Ent näiteks riigireetmise eest kurjategija hukati ja lisaks võidi hävitada ka tema vanemate ja naise suguvõsa. Keelatud kirjanduse ja võimu kritiseerimise eest ootas samuti hukkamine koos perekonnaliikmetega. Hukkamisviiside seas olid seadustatud näiteks neljaks rebimine, pooleks või tükkideks raiumine, pea maharaiumine ja teiba otsa torkamine, aeglane kägistamine, elusalt matmine, elusalt keetmine, kontide murdmine. Hirm selliste kohutavate karistuste ees oli siiski niivõrd suur, et vastavaid kuritegusid ja hukkamisi tuli ette suhteliselt harva. Seevastu palju enam kasutati nn raske töö karistusi, nagu sunnitööle või riigiorjusesse mõistmine, töölesaatmine Suure Müüri, piirikindluste, paleede või templite ehitusele, millest riik sai ka odavat tööjõudu. Üsna tihti mõisteti karistuseks või lisakaristuseks füüsiline sandistamine: kastreerimine, põlvekõõluste läbilõikamine, nina või kõrvade äralõikamine, pimedakstegemine ja häbimärgistamine tulise rauaga. Tavalisim karistusviis oli aga ihunuhtlus, eriti peksmine pillirookepiga jalataldadele, mida sõjaväes kasutati teinekord koguni distsipliinirikkumiste ennetamiseks (Sima Qian 1975: 75-81; Perelomov 1962: 132-140; Perelomov 1981: 191-204; Krjukov \& Perelomov \& Sofronov \& Tšeboksarov 1983: 344 jj). 
Qini riigi seadusandluses kehtestati julmad karistused eelkõige riigi vastu suunatud kuritegude eest, isikuvastutuse ees domineeris ühisvastutus, seaduste tõlgendamisel kehtis põhimõte: see, mis ei ole lubatud, on keelatud. Seaduste täitmise järele valvas arvukas järelevalve- ja sunniaparaat.

\subsection{Ideoloogia. Meetmed religiooni vallas}

Li Si ise valvas kommete ja kultuse järele, talle allus ka riigi ülempreester. 213. aastal eKr algas legistlikule riigile ohtliku ja vabamõtlemist soodustava konfutsianistliku kirjanduse hävitamine, 212. aastal algasid riigiametnike regulaarsed profülaktilised ülekuulamised. Seadus nõudis, et tuli hukata kõik Kong Fuzi õpetuse suuliselt levitajad ehk need, kes ütlevad, et vanasti oli parem. Ametnik, kes ei teatanud vastavast seaduserikkumisest, langes sama karistuse alla. Üle 460 konfutsianistliku õpetlase maeti elusalt, ülejäänud saadeti riigist välja. Umbes samal ajal algas keelatud konfutsianistlike raamatute hävitamine. Loodi vastav nimistu. Need, kes konfutsianistlikke raamatuid 13 päeva jooksul ära ei põletanud, saadeti ahelais neljaks aastaks Suurt Müüri ehitama. Hävitati muide vaid erakogude keelatud kirjandus, riiklikesse raamatukogudesse jäeti teatud arv eksemplare alles ja asutati $\mathrm{nn}$ erifondid. Ei hävitatud praktilisi nõuandeid jagavaid raamatuid - meditsiini-, farmaatsia-, ennustamis- ja põllumajandustekste. Alles jäeti Qini ajalooannaalid, kuid teiste riikide kroonikad enamasti hävitati. Ajaloo tsenseerimisega, millega oli tegelnud juba Shang Yang, tahtis Li Si läbi lõigata rahva mässumeelsuse juured. Niisiis oli konfutsianism keelatud, Hiina muistne animistlik loodus- ja taevakultus oli seevastu lubatud ja soositud religioon. Riigi tasemel kuulutati hiinlaste ülimuslikkust ning seda rakendati ka alistatud rahvaste valitsemisel.

Riigiideoloogias laskis Li Si juurutada ka kõikvõimsa ja jumaliku keisri kultust. Pidevalt kuulutati rahvale, et keiser on tark ja ettenägelik, ta töötab varahommikust hilisööni rahva hüvanguks, kõik mehed ja naised elavad seaduste järgi ja kõik inimesed täidavad oma kohust, riigis valitseb rahu ja kord. Sellist teksti sisaldavad mitmed säilinud kiviraidkirjad. Keisril oli tõesti suur töövõime, ta olla lugenud päevas läbi ligi $30 \mathrm{~kg}$ dokumente. Viimastel aastatel põdes Qin Shi Huangdi jälitusmaaniat, ei peatunud ega elanud kaua ühes ja samas kohas, ei informeerinud ärasõidust isegi lähedasi abilisi. 200 lii raadiuses pealinnast oli tal 270 paleed, mis olid alati valmis valitsejat vastu võtma. Keisri asupaika teadsid vähesed; kes teadis ja lobises, see hukati. Hoolimata repressioonidest ja ideoloogilisest puhastusest vaimne opositsioon ometi tugevnes (Sima Qian 1975: 66, 77, 79-81; Perelomov 1962: 
153-166; Perelomov 1981: 191-204; Krjukov \& Perelomov \& Sofronov \& Tšeboksarov 1983: 335; Durrant 1987: 499).

Qini riigis oli niisiis legistlik riigiõpetus koos animistliku taevakultusega kuulutatuid ametlikuks riigiusundiks. Konfutsianism religiooni ja filosoofiana, samuti teised filosoofiad olid keelatud. Lisandus mütologiseeritud keisrikultus, doktrineeritud etnotsentrism ning eesmärgipäraselt suunatud haridus- ja kultuuripoliitika koos teabe ja ajalookäsituse tsenseerimisega mõtlemise unifitseerimise eesmärgil.

\subsection{Sõjavägi ja agressiivne välispoliitika}

Seoses vana aristokraatia jätkuva mässumeelsusega laskis keiser 215. aastal eKr hävitada kuue allutatud riigi kaitseehitised ja muud riigisisesed kindlustused, välja arvatud need, mis paiknesid riigi põhjapiiridel, kus algas Suure Müüri ehitamine. Sõjaväkke mobiliseeriti mehi alates 23. eluaastast. Sõjaväekohustus koosnes kolmest osast: esmalt 23-aastaste kuuajaline sõjaväeteenistus provintsis, seejärel aastane teenistus regulaarvägedes ja lõpuks aastane teenistus piirikaitses. Sõjaväeteenistusest oli võimalik vabaks osta. Vabastus pikaajalisest sõjaväeteenistusest maksis 2000 münti, piirivalvest küll vaid 300 münti. See oli kallis, sest riik vajas sõdureid ja eelkõige maakehvistu pidi sõjaväeteenistuse läbi tegema. Ent ka aristokraatia pidi kandma sõjaväeteenistuskohustust, sest muidu ei saanud ametniku auastet.

Qin Shi Huangdi ja Er Shi Huangdi pidasid Hiina põhja- ja lõunapiiridel arvukalt vallutus- ja kaitsesõdu. Kaitse-eesmärgil algas 215. aastal eKr Suure Hiina Müüri ehitamine, mis kestis sajandeid. Ehitustöödel hukkus juba Qini impeeriumi ajal sadu tuhandeid inimesi (Sima Qian 1975: 74-75; Perelomov 1962: 166-174; Perelomov 1981: 191-204; Krjukov \& Perelomov \& Sofronov \& Tšeboksarov 1983: 105-110).

Qini riik lõi hiiglasuure regulaararmee, mille eesmärgiks oli poliitilise hegemoonia taotlemine naaberterritooriumide suhtes ja agressiivse välispoliitika süstemaatiline teostamine.

\section{Järeldused}

Legistlik riigivalitsemisteooria, mis oli suunatud valitseja täieliku kontrolli kehtestamisele ühiskonna üle ja keskvõimu tugevdamisele, on teadaolevalt esimene totalitaarse riigivõimu põhjendamise teooria maailma ajaloos. Fajia teooria autorid tegid ka rea vähem või rohkem õnnestunud katseid sellist 
riigivalitsemissüsteemi ellu viia. Kõige kaugemale fajia süsteemi rakendamisel keisririigis jõudis Qin Shi Huangdi aegne minister Li Si.

Sima Qiani kroonika analüüs näitab, et arvesse võttes kättesaadavaid andmeid Qini riigi loomise ja kokkuvarisemise, valitsemissüsteemi ülesehituse, majandusmeetmete, ühiskonnakorralduse, õigussüsteemi, religioonipoliitika ja ideoloogia, samuti armee ja välispoliitika kohta, oli antud juhul kindlasti tegemist varatotalitaarse riigiga, pealegi ilmselt maailma esimese totalitaarse suurriigiga.

\section{Kommentaarid}

${ }^{1}$ Artikkel on seotud Eesti Teadusfondi grandiga nr 5374.

${ }^{2}$ Hiina nimed on kirjutatud pinyin-transliteratsioonis.

${ }^{3}$ Valmistati 12 pronkskuju, igaüks neist kaalus $29960 \mathrm{~kg}$.

${ }^{4}$ Korduvate ebaõnnestunud atentaatide tõttu oli Qin Shi Huangdi oma elu pärast mures. Ta saatis isegi mereekspeditsiooni endale surematuserohtu otsima (Sima Qian 1975: 71-74).

${ }^{5}$ Qin Shi Huangdi hauda ehitas 700000 kurjategijat ja orja. Temaga koos maeti kõik ta liignaised, palju orje ja eunuhhe, samuti meistrid ja arhitektid (Sima Qian 1975: 87).

\section{Kirjandus}

Durrant, Stephen W. 1987. Legalism. Eliade, Mircea (toim). The Encyclopedia of Religion 16. New York: Macmillan Publishing Company, lk 497-499.

Krjukov, Mihhail 1972 = Кљюков, Михаил. Пљедисловие: Сыма Цянь и его 'Истољические записки’. Сыма Цянь (= Sima Qian). Ши изи [Истољические записки] 1. Москва: Наука, lk 12-65.

Krjukov \& Perelomov \& Sofronov \& Tšeboksarov 1983 = Кљюков, Михаил \& Пељеломов, Леонаљд \& Софљонов, Михаил \& Чебоксаљов, Николай. Дьвебние китайци 6 эпоху центльализованныхх илие.ьий. Москва: Наука.

Kulmar, Tarmo 2003 (2005). Totalitarianism and the Role of Religion in the Inca State. Folklore:An Electronic Journal of Folklore 23, lk 25-39 (http://www.folklore.ee/folklore/ vol23/incastate.pdf - 6. detsember 2006).

Perelomov 1962 = Пељеломов, Леонаљд. Илиелия Цинь - пељьое иентььлизованное восуда.ьст6о 6 Kитае (221-202 в. до н. э.). Москва: Изд-во восточ. лит.

Perelomov 1981 = Їељеломов, Леонаљд. Конфуиианство и левиз.и 6 политицеской исто.ьии китая. Москва: Наука. 
Sima Qian 1975 = Сыма Цянь. Ши изи [Истољические записки] 2. Москва: Наука.

Shang Yang 1993 = Шань Ян. Шан Цзюнь Шу [Книга пљавителя области Шан]. Perelomov, Leonard (tõlk \& komment). Москва: Научно-издательский центљ Ладомиљ.

Vassiljev 1989 = Васильев, Деонид. Пльоблель генезиса китайской льсли: Фольии.ьование основ лильовоззљения и менталитета. Москва: Наука.

Vjatkin 1972 = Вяткин, љомуалд. Введение: “Основные записи” как истољический источник. Сыма Цянь. Ши изи [Истољические записки] 1. Москва: Наука, 1972, pp. 66-130.

\section{Summary}

\section{On the System of Government in Qin Empire in Ancient China}

\section{Tarmo Kulmar}

Key words: Ancient China, Qin Empire, earliest totalitarianism, legalism, state power, ideology, society.

The article demonstrates that the Inca State was not the first or only early totalitarian state of its kind, we can find an even more obvious precedent for an early totalitarian state from ancient Chinese history, namely in the Qin Empire. The legalist political theory, which was aimed at establishing the ruler's absolute control over the society and consolidating the central authority, is the first theory justifying totalitarian power known in world history. The authors of the Fajia theory made a number of more or less successful attempts to implement a system of government based on it. The analysis of Sima Qian's chronicle and the main arguments of the studies based on it shows that in view of the existing knowledge of the foundation and collapse of the Qin Empire, of the structure of its system of government, economic measures, ordering of society, legal system, policy of religion and ideology as well as its armed forces and foreign policy, can certainly be identified as the first totalitarian superpower in world history. 